\title{
Proceeding
}

Supplementary Issue: Spring Conferences of Sports Science. Costa Blanca Sports Science Events, 19-20 June 2020. Alicante, Spain.

\section{Transplant recipients' motivational orientation towards sport participation and physical activity enjoyment at the 2019 World Transplant Games in Newcastle-Gateshead UK}

\author{
JULIUS JOOSTE $\triangle$, DANIEL ROGERSON, MITCHELL HOGG, SCOTT HOUGHTON \\ Department of Psychology, Northumbria University, Newcastle upon Tyne, United Kingdom
}

\begin{abstract}
This study adopted a descriptive correlational design to identify organ transplant athletes' motivational behaviour and level of physical activity enjoyment during the 2019 World Transplant Games. The causal relationship between motivational behaviour and enjoyment was also determined. Data was collected through questionnaires during the event that tapped participants' demographic information and responses to the Task and Ego Orientation Questionnaire, Sport Motivation Scale-2 and Physical Activity Enjoyment Scale. Descriptive statistics revealed that transplant athletes $(n=119$; Mage $=52.92$ years, $S D=13.51)$ find sport mostly enjoyable whilst holding a strong task-oriented approach towards sport participation with high approximations of intrinsic, integrated and identified motivation. Male and female athletes also shared a relatively similar motivational profile with male athletes reporting significantly higher levels of sport enjoyment compared to their female counterparts. Inferential statistics further revealed significant associations between most dimensions of motivation and level of enjoyment, of which gender and certain aspects of motivation were exposed as significant predictors of athletes' reported enjoyment in sport. It is advised that autonomous regulatory behaviours be garnered in transplant recipients looking to start/continue sport participation as it proved to be prime correlates and determinants of enjoyment in sport.

Keywords: Enjoyment; Motivation; Organ transplant athletes; Perception of success; Sports.

Cite this article as:

Jooste, J., Rogerson, D., Hogg, M. \& Houghton, S. (2020). Transplant recipients' motivational orientation towards sport participation and physical activity enjoyment at the 2019 World Transplant Games in Newcastle-Gateshead UK. Journal of Human Sport and Exercise, 15(3proc), S481-S494. doi:https://doi.org/10.14198/jhse.2020.15.Proc3.02

Corresponding author. Department of Psychology, Northumbria University, Northumberland Building, Newcastle upon Tyne, NE1 8ST, United Kingdom. https://orcid.org/0000-0003-3278-0040

E-mail: julius.jooste@northumbria.ac.uk

Supplementary Issue: Spring Conferences of Sports Science. Costa Blanca Sports Science Events, 19-20 June 2020. Alicante, Spain.

JOURNAL OF HUMAN SPORT \& EXERCISE ISSN 1988-5202

(c) Faculty of Education. University of Alicante

doi:10.14198/jhse.2020.15.Proc3.02
\end{abstract}




\section{INTRODUCTION}

Introduced in 1978, the World Transplant Games (WTG) is held on a two-yearly basis with winter games in the intervening years (introduced in 1994) to promote physical activity and sport post-transplant surgery and raise global awareness of the benefit of organ and tissue donation (World Transplant Games, 2019). Moreover, the WTG is a worldwide cause-related event that not only commemorates the gift of life, but also demonstrates gratitude towards the organ donors and allied health services (Neale, Smith, \& Bishop, 2017). In 2019, the WTG tournament held within the UK (Newcastle-Gateshead), attracted an estimated 1500 competitors from 59 countries to compete across sixteen different sports.

Although event-specific qualifying standards have been imposed by certain countries to permit national representation and/or funding, entry to the WTG is open to all life-supporting organ (allographs), bone marrow and/or haemopoietic cell transplants recipients who are subjected to post-transplant immunosuppressive therapy (World Transplant Games, 2019). Whilst the representation of transplant athletes has increased on a world scale in recent years (Wright, Bloxham, Hames, \& Price, 2019), there has also been an accompanying positive change witnessed in public opinion on organ donation (Aijing, Wenzhao, Wei, Qiquan, \& Xuantong, 2016) alongside ongoing improvements in surgical procedures, donor recruitment, organ preservation and immunosuppressive therapies (Neale et al., 2017). Laws and regulations in several countries have also been revised to address the build-up of people currently waiting for a transplant. For example, since the $20^{\text {th }}$ of May 2020 the UK's law on organ donation (Max and Keira's Bill) embraces an 'opt-out system' where all residents over the age of 18 years (except if from an excluded group) are considered as consented organ donors upon death (GOV.UK, 2019).

Behaviours towards the adoption or continuation of exercise and sporting activities among organ transplant recipients (OTR) have been sparsely reported by prior literature, but indicates that common motives cited for engagement range from perceived competence to health and well-being benefits (Neale et al., 2017). Previous research conducted during an earlier WTG event revealed that enjoyment, perceived competence and health function serve as prime motivating factors for transplant recipients to participate in sport (Johnson, Hinic, Billström, \& Gäbel, 2013). Another study that explored the leisure-motivations among transplant athletes revealed that social impact (i.e. to change public opinion, create awareness) and social motives (to interact and meet new people) are most strongly represented for taking part in a cause-related event such as the WTG (Derom, 2009). Despite showing parallels in motives for sports participation to the general public, factors such as altered body composition, health-related depression, social isolation (Slapak, 2005), the accompanying side-effects of immunosuppressant drugs, and the underlying disease process impose additional barriers on transplant recipients' efforts and ability to engage in sport or exercise activities (Neale et al., 2017). Physical limitations such as inadequate physical and exercise capacity, poor muscle strength, insufficient energy levels, fear and comorbidities are among the salient physical barriers to sport or exercise. Other social barriers include the lack in availability of personnel with expertise on the special precautions and considerations of sport participation post-transplant surgery (van Adrichem et al., 2016). Moreover, findings derived from semi-structured interviews with solid organ transplant recipients $(n=16)$ revealed that aspects of motivation are the most mentioned psychological barrier and facilitator to physical activity (van Adrichem et al., 2016). Quantitative views obtained from a sample of kidney and kidney-pancreas transplant recipients corroborated this notion stressing that a lack of motivation is the most repeatedly reported impediment to engaging in physical activity (Sanchez et al., 2007).

Extant theoretical frameworks describe motivation in sport as the need for development, mastery and feat (Ryan \& Deci, 2017). In this regard, the application of the Self-Determination Theory [SDT] (Deci \& Ryan, 
1985) and Achievement Goal Theory [AGT] (Nicholls, 1984; 1989) have aided in understanding the complex nature that underlies motivational comportment in sport and exercise settings alike. Moreover, the SDT maintains that individuals are motivated to satisfy the need for competence (mastery of the environment), autonomy (self-imposed and purposefully enacted), and relatedness (connected, and cared for by significant others); these concepts are exemplified by behaviour that ranges from amotivation (i.e. lack intention to act) to intrinsic regulation with extrinsic regulation covering the divide between the opposite ends of the continuum (Ryan \& Deci, 2017). External regulatory motivation (least autonomous) stems from the need to gain rewards or by avoiding negative experiences (e.g. to win or avoid losing); it is also fuelled by an introjected sense of seeking social approval (pride) and avoiding disapproval (shame). Conversely, internal regulatory motivation (most autonomous) emanates from inherent feelings of interest and value (Deci \& Ryan, 2012; Ryan \& Deci, 2017). Thus implying that athletes who are internally motivated will exercise and compete without any external contingencies, which is revealed to be a stronger predictor of athletes' level of vitality (Nix, Ryan, Manly, \& Deci, 1999), performance, persistence and sustained participation (Ryan \& Deci, 2007; Vallerand, 2007) compared to external regulatory motivation. Athletes who are externally motivated are often disheartened by defeat (lack of perceived competence) and the uncontrollability (autonomy) over the outcome of performance (Weinberg \& Gould, 2018). However, the Cognitive Evaluation Theory (CET - Deci \& Ryan, 1985), which is a sub-theory within the SDT postulates that negative social environments (e.g. a coach's controlling behaviour and negative performance feedback) can forestall one's intrinsic motivation if the need for autonomy, competence and relatedness becomes thwarted (Ryan \& Deci, 2000). Consequently, an athlete who is highly internally motivated can also become extrinsically motivated when instrumentalities (i.e. perceived competence and relatedness) associated with outcome goals are emphasised (Weinberg \& Gould, 2018). Despite the environmental influences on athletes' regulatory drive, in the expansion of the SDT research suggests that athletes' satisfaction of the need for competence and relatedness are strongly predictive of their orientation towards task-mastery in sport (Sari, 2015).

In this respect, the Achievement Goal Theory (AGT; Nicholls, 1989) offers a social-cognitive approach to explain individuals' motivational orientation in achievement situations such as in sport. According to the AGT individuals are primarily motivated to develop competence (Nicholls, 1989) and that the quality of their affective, cognitive, and behavioural experiences are strongly determined by their personal theory of achievement and discernment of the motivational/social climate. Nicholls (1989) asserted that individuals' cognitive attributions of achievement stems from differentiated (effort and ability is separated) and undifferentiated (effort and ability is not separated) vantage points referred to as task and ego-involved orientation respectively. Based on this notion, athletes' intentional and goal-directed behaviour in sport is a function of their interpretation of competence and satisfaction, which is either based on self-improvement (task orientation) or demonstration of normative and social superiority (ego orientation). These different cognitive interpretation of competence can hold implications for adaptability within sports as research suggest that a high task/low ego orientation towards participation ensures more adaptive motivational, behavioural, approaches (Standage, Duda, \& Pensgaard, 2005), increased exertion, and development (Ntoumanis \& Biddle, 1999). Gregg, Jenny, and Hall (2016) added that athletes who exhibit high task orientation prove to be essentially more motivated, more skilled in forming mastery images and are better in experiencing emotions of their images compared to high ego-oriented counterparts.

The profound importance of motivational behaviour remains a focus area in sport studies due to the significant influence it has on athletes' well-being (Milyavskaya \& Koestner, 2011), subjective vitality (Adie, Duda, \& Ntoumanis, 2008), flow and engagement (Hodge, Lonsdale, \& Jackson, 2009), as well as enjoyment in sport (Schneider, Harrington, \& Tobar, 2017). Remarkably, enjoyment is a key correlate of regular physical activity (Sallis, Prochaska, \& Taylor, 2000) and crucial motivational factor in sport based on its positive association 
with continued participation and exercise adherence (Visek et al., 2015). Lack of enjoyment is also a common predictor of dropout from sport (Crane \& Temple, 2015; Gardner, Magee, \& Vella, 2017) and levels of amotivation (Sánchez-Miguel, Leo, Sánchez-Oliva, Amado, \& García-Calvo, 2013).

Additionally, findings from a small number of related studies have revealed strong links between athletes' level of enjoyment and motivational orientation (Duda, Fox, Biddle, \& Armstrong, 1992; Liukkonen, 1998; Romanová \& Sollár, 2019; Yli-Piipari, Barkoukis, Jaakkola, \& Liukkonen, 2013), as well as perceived competence and mastery (Cairney et al., 2012; Wallhead \& Buckworth, 2004). For example, a study that categorised a large sample $(n=557)$ of 14 -year-old male Finnish soccer players according to their achievement goals (perception of success) reported the highest level of enjoyment in the high task/low ego orientation subgroup. Comparable results were evident in sub-groups who reported high levels of mastery training and competing climates (Liukkonen, 1998). Based on the views of young male Balearic Islands football players $(n=454)$, Garcia-Mas et al. (2010) added that extrinsic motivation proved to be a stronger predictor of enjoyment than intrinsic motivation whilst amotivation contributed negatively to players explanation of enjoyment. Although these findings are based on homogenous school-aged children, research involving a heterogenous sample of master athletes aged from 29 years to 77 years (mean $=48$ years) from six different sports reveal that those high in social motivation (affiliation \& status) moderate task, and low ego orientation, scored the highest on enjoyment compared to other cluster groups (Hodge, Allen, \& Smellie, 2008). Hence, verifying prominent links between dimensions of motivation and enjoyment.

Whilst past research has, to some extent, confirmed correlational pathways between motivation and perceived sport-related enjoyment, the implications of transplant surgery such as muscle weakness, decreased aerobic capacity and reduced exercise tolerance (Didsbury et al., 2013) on transplant athletes' motivational experiences should not be overlooked and accepted to be comparable to other sporting populations. Research informing expert guidance on specific sport populations such as transplant athletes is still desperately sought (van Adrichem et al., 2016). Sports and exercise play a vital role in the physiological and psychological rehabilitation of OTR (Slapak, 2005) of which enjoyment of physical activity significantly and positively associates with a sense of psychological well-being and health (Johnson et al., 2013). Based on this notion, it is believed that broader research on transplant athletes' motivational behaviour towards sport participation and its links to enjoyment is not only needed to address gaps in literature, but also pivotal to inform key role players in transplant recipients' social environments. This includes the support given by caretakers, coaches, physical therapists, sport psychologists and event organisers in their efforts to initiate, revive and sustain sport participation. In this respect, Wright et al. (2019) cautioned that practitioners working with OTR need to be knowledgeable and prudent in their approach.

In light of this, the present investigation was guided by the following research questions: (i) 'What is the motivational orientation and level of physical activity enjoyment of organ transplant athletes?', and (ii) 'What is the relationship between their motivational behaviour and level of enjoyment in sport participation?'. It is hypothesised that transplant athletes will mostly exhibit task mastery achievement goals in sport along with associative levels of constructive motivational behaviour (such as intrinsic, identified, and integrated dimensions) that is complemented by moderate to high levels of enjoyment. Athletes' motivational behaviour will also be significantly and causally related to their level of sport enjoyment. 


\section{MATERIALS AND METHODS}

\section{Participants}

Transplant recipient athletes from English-speaking nations who attended the 2019 WTG were requested to complete either an online or pen-and-paper survey that consisted of demographic questions and several standardised sport-related psychological scales. A total of 135 athletes voluntarily participated in the study of which data from 121 athletes (79 males \& 42 females who have completed all the involved measures) were considered for analyses in the present study. The sample had a mean age of 52.92 years (minimum = 18 , maximum $=81, S D=13.51$ ) with the majority $(42 \%)$ reporting to be in full-time employment, $28.1 \%$ retired, $7.4 \%$ in part-time employment and the remainder being either a student, self-employed, unemployed or other. The majority $(56.7 \%)$ of the participants held an undergraduate qualification at the time of participation with $26.6 \%$ reporting to have a post-graduate degree (Masters $=18.2, \mathrm{PhD}=8.3)$. Most of the participants $(51.2 \%)$ had a kidney transplant while others reported being recipients of liver $(24 \%)$, heart $(15.7 \%)$, pancreas $(8 \%)$, cell $(6 \%)$, and lung (5\%) transplants, which also included multiple organ transplants in some athletes. The time since last transplant surgery during the time of the event ranged from less than 1 to 38 years (Myear = 10.51; $S D=8.364$ ).

\section{Procedures}

The investigation received the necessary ethical approval by the Department of Psychology Ethics Committee at Northumbria University prior to the start of data collection. Transplant recipient athletes' participation in the study was requested in person by the involved investigators. Flyers containing a web link to the online survey (via Qualtrics) were also handed out to athletes at competition venues during the event, as well as notices posted on WTG social media platforms and email requests sent to the team managers for athletes' voluntary participation. Information sheets that clarify the nature, purpose and inclusion criteria set for participation in the investigation were provided, and informed consent was sought before the participants were able to access the remainder of the online survey or before they were allowed to complete the pen-andpaper questionnaires. Debrief information was provided after the completion of the survey containing the investigators' contact details and instructions on how to withdraw data from the study up to the point of a formal report.

\section{Measures}

The survey used in the investigation consisted of demographic background questions and several well-known psychological Likert scale instruments used for research, profiling and follow-up evaluation in sport and exercise settings.

Demographic questions included age, gender, nationality, sport, employment status, level of qualification, type of transplant, and time since most recent transplant.

The Task and Ego Orientation in Sport Questionnaire (TEOSQ - Duda \& Whitehead, 1998) was utilized to measure athletes' dispositional differences in goal orientation based on their subjective views of success in sport. The TEOSQ prompts respondents' agreement to 13 statements (dedicated to two subscales namely task \& ego motivation) using a Likert scale that ranges from 1 (Disagree a lot) to 5 (Agree a lot). Task motivation is represented by seven statements for example, "I feel the most successful in sport when I learn something new by working hard" and ego motivation by six statements for example, "I feel the most successful in sport when I am the best". The TEOSQ has revealed high internal consistency among a previous sample of transplant athletes with a Cronbach's alpha value of .81 for task motivation and .80 for ego motivation (Johnson et al., 2013). 
A revised version of the original 18-item Physical Activity Enjoyment Scale (PACES - Kendzierski \& DeCarlo, 1991) was used to measure the positive effect associated with athletes' involvement in sport. The revised PACES (Motl et al., 2001) contains 16 bipolar statements (positive \& negative) which begin with the stem "When I am physically active..." that are each rated on a Likert scale ranging from 1 (Totally disagree) to 7 (Totally agree) based on the respondent's agreement. Examples of statements are: "I find it pleasurable"; "It makes me sad", which were summed to produce a total enjoyment score out of a maximum score of 112. Validation of the PACES has revealed it to be internally consistent with a Cronbach's alpha of 89 (Kendzierski \& DeCarlo, 1991).

Athletes' level of motivation towards sport participation was measured with the Sport Motivation Scale in Sport-2 (SMS-2 - Pelletier, Rocchi, Vallerand, Deci, \& Ryan, 2013). This revised version contains 18 items representative of six dimensions of motivation namely intrinsic (e.g. "Because it gives me pleasure to learn more about my sport"), integrated (e.g. "Because practising sports reflects the essence of whom I am"), identified (e.g. "Because I have chosen this sport as a way to develop myself"), introjected (e.g. "Because I feel better about myself when I do"), external (e.g. "Because people around me reward me when I do"), and amotivation (e.g. "So that others will praise me for what I do"). Respondents rate their level of agreement to the items on a Likert scale that ranges from 1 (Not at all agree) to 7 (Completely agree). There are three items per subscale and participants' scores are calculated by computing a mean score for each subscale. Acceptable reliability of the SMS-2 was reported during the revision of the measure with Cronbach's alpha values ranging from .76 to .86 for the six dimensions (Pelletier et al., 2013).

\section{Analyses}

The IBM Statistical Package for The Social Sciences (SPSS) version 26 was used to analyse the data. Before the analyses, the data were cleaned to remove incomplete surveys from the data set. Missing values noted on the SMS-2 and PACES revealed to be missing at random (Little's MCAR: $\chi^{2}=12.74, \mathrm{df}=30, p>.05$ ) and were replaced using the series mean function in SPSS where after values that were identified as extreme outliers (through boxplots at the interquartile range rule of multiplier 3) were subjected to 'windsorization' (Tukey, 1962). Further exploration of the data revealed it to be statistically significantly different from a normal distribution (Shapiro-Wilk values < .05). Cronbach's alpha coefficients were computed to examine the reliability of the instruments. Descriptive statistics such as minimum and maximum values, means, and standard deviations were used to analyse the data where after a Mann-Whitney $U$ test (relevant assumptions for this test were met) was performed to identify gender differences in the assessed variables. In this respect, the effect size of this difference was also determined (using the following equation $\eta^{2}=Z^{2} / N-1$ ). Spearman's rank-order correlation (rho) was used to assess the association between the motivation variables and level of enjoyment ensued by hierarchical multiple regression analyses (with wild Bootstrap set at 2000 sample and $95 \%$ Confidence Interval to correct for non-normality in the data). Consistent with other sport research, Johnson et al. (2013) advised on the potential influence age and gender might have on transplant athletes' sport participation experiences. Therefore, it was necessary to control for these variables in the latter analyses.

\section{RESULTS}

The PACES and sub-scales of the motivation measures had adequate and fairly high reliabilities (ranging from .67 to .85$)$, except for the introjected and amotivation subscales that revealed low to moderate reliability of .52 and .56 respectively. However, these are still considered acceptable $(>.5)$ due to the nature of the research being exploratory and the limited number of items in each of these sub-scales (Hinton, McMurray, \& Brownlow, 2014). Overall, the participants demonstrated a strong task-oriented approach (M = 4.08; SD = 
.49) towards sport participation with fairly high approximations of intrinsic $(M=5.39, S D=1.18)$, integrated $(M=5.32, S D=1.41)$ and identified $(M=5.27, S D=1.25)$ motivation. Results also indicated that athletes find sport participation enjoyable $(M=98.56, S D=12.76)$. Male and female athletes largely reflected a similar motivational orientation towards sport participation with males reporting significantly higher levels of physical activity enjoyment $(Z=-3.56, p<.01)$ (See Table 1).

Table 1. Descriptive statistics, reliability, and Mann-Whitney $U$ results (valid $n=121$ listwise).

\begin{tabular}{|c|c|c|c|c|c|c|c|c|c|c|c|}
\hline \multirow[t]{2}{*}{ Variables } & \multicolumn{6}{|c|}{ Participants } & \multicolumn{2}{|c|}{ Gender } & \multicolumn{3}{|c|}{ Mann-Whitney U } \\
\hline & $\mathrm{N}$ & Min & Max & Mean & $\begin{array}{c}\text { Std. } \\
\text { Deviation }\end{array}$ & $\begin{array}{c}\text { Cronbach's } \\
\text { a }\end{array}$ & Males & Females & Z & $\begin{array}{c}\text { Asymptotic Sig. } \\
\text { (2-tailed) }\end{array}$ & $\eta^{2}$ \\
\hline Task & 121 & 2 & 5 & 4.08 & .49 & .76 & 4.12 & 4.00 & -1.02 & .31 & .01 \\
\hline Ego & 121 & 1 & 4 & 2.42 & .77 & .82 & 2.52 & 2.23 & -1.94 & .05 & .03 \\
\hline Intrinsic & 121 & 2 & 7 & 5.39 & 1.18 & .81 & 5.44 & 5.28 & -1.16 & .25 & .01 \\
\hline Integrated & 121 & 1 & 7 & 5.23 & 1.41 & .85 & 5.39 & 4.93 & -1.63 & .10 & .02 \\
\hline Identified & 121 & 1 & 7 & 5.27 & 1.25 & .82 & 5.34 & 5.13 & -.95 & .34 & .01 \\
\hline Introjected & 121 & 1 & 7 & 4.33 & 1.20 & .52 & 4.33 & 4.31 & .14 & .89 & 1.63 \\
\hline Extrinsic & 121 & 1 & 4 & 1.87 & .93 & .67 & 1.82 & 1.97 & .40 & .69 & .00 \\
\hline Amotivation & 121 & 1 & 5 & 1.73 & .81 & .56 & 1.72 & 1.76 & .15 & .88 & .00 \\
\hline Enjoyment & 121 & 59 & 145 & 98.56 & 12.76 & .80 & 100.96 & 94.05 & -3.56 & $.00^{*}$ & .12 \\
\hline
\end{tabular}

Note. Difference is significant at the .01 level (2-tailed).

Spearman's rho analyses revealed several weak to moderate associations between the variables. More specifically the task $\left(r_{s}=.32, p<.01\right)$, intrinsic $\left(r_{s}=.46, p<.01\right)$, integrated $\left(r_{s}=.37, p<.01\right)$, and identified $\left(r_{s}=.47, p<.01\right)$ dimensions of motivation were significantly and positively associated with athletes' level of enjoyment whilst extrinsic $\left(r_{s}=-.22, p<.05\right)$ and amotivation $\left(r_{s}=-.32, p<.01\right)$ revealed to be negatively related to enjoyment (See Table 2).

Table 2. Correlation between motivation variables and enjoyment $(n=121)$.

\begin{tabular}{|c|c|c|c|c|c|c|c|c|c|c|}
\hline Spearman's rho & & 1 & 2 & 3 & 4 & 5 & 6 & 7 & 8 & 9 \\
\hline Task 1. & $\begin{array}{l}\text { Coefficient } \\
\text { Sig. }\end{array}$ & 1.00 & & & & & & & & \\
\hline \multirow{2}{*}{ Ego 2.} & Coefficient & .06 & 1.00 & & & & & & & \\
\hline & Sig. & .52 & . & & & & & & & \\
\hline \multirow{2}{*}{ Intrinsic 3.} & Coefficient & $.56^{\star *}$ & .06 & 1.00 & & & & & & \\
\hline & Sig. & .00 & .50 & . & & & & & & \\
\hline \multirow{2}{*}{ Integrated 4} & Coefficient & $.32^{* *}$ & .15 & $.43^{* *}$ & 1.00 & & & & & \\
\hline & Sig. & .00 & .10 & .00 & & & & & & \\
\hline \multirow{2}{*}{ Identified 5.} & Coefficient & $.44^{* *}$ & -.03 & $.63^{* *}$ & $.56^{* *}$ & 1.00 & & & & \\
\hline & Sig. & .00 & .73 & .00 & .00 & - & & & & \\
\hline \multirow{2}{*}{ Introjected 6.} & Coefficient & .15 & .15 & $.19^{*}$ & $.39^{* *}$ & $.25^{\star *}$ & 1.00 & & & \\
\hline & Sig. & .10 & .11 & .03 & .00 & .01 & 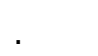 & & & \\
\hline \multirow{2}{*}{ Extrinsic 7.} & Coefficient & -.07 & $.23^{*}$ & -.07 & .06 & -.14 & $.40^{* *}$ & 1.00 & & \\
\hline & Sig. & .45 & .01 & .42 & .55 & .14 & .00 & & & \\
\hline \multirow{2}{*}{ Amotivation 8.} & Coefficient & -.14 & $.27^{\star \star}$ & -.12 & .01 & $-.20^{*}$ & .13 & $.64^{* *}$ & 1.00 & \\
\hline & Sig. & .14 & .00 & .18 & .91 & .03 & .14 & .00 & & \\
\hline \multirow{2}{*}{ Enjoyment 9.} & Coefficient & $.32^{* *}$ & -.11 & $.46^{* *}$ & $.37^{* *}$ & $.47^{* *}$ & .10 & $-.22^{*}$ & $-.32^{* *}$ & 1.00 \\
\hline & Sig. & .00 & .24 & .00 & .00 & .00 & .29 & .02 & .00 & \\
\hline
\end{tabular}
Note. ${ }^{* *}$. Correlation is significant at the .01 level (2-tailed). *. Correlation is significant at the .05 level (2-tailed). 
To further explore the relationship between athletes' motivational orientation and level of enjoyment, a series of hierarchical multiple regression analyses (with wild Bootstrap set at 2000 sample and $95 \% \mathrm{Cl}$ ) were performed with age and gender as confounding variables entered at step one and the motivation variables (predictor variables) at step two (see Table 3).

In step one, age and gender contributed significantly to the regression model $[F(2,118)=4.38, p<.05]$ and explained $6.2 \%$ of the variance in enjoyment. The motivation variables introduced in step two of the regression, accounted for an additional $36.2 \%[F(10,110)=8.33, p<.01]$ of the variance in athletes' level of enjoyment with integrated motivation exerting a significant positive influence $(2.86,95 \% \mathrm{BCa} \mathrm{Cl}[.72,4.10]$, $\mathrm{p}<.01)$ and amotivation a significant negative influence $(-3.77,95 \% \mathrm{BCa} \mathrm{Cl}[-7.56,-1.68], \mathrm{p}<.01)$ on enjoyment. Athletes' gender also revealed to have strong predictive utility suggesting that males are more likely to derive enjoyment from sport participation $(-5.22,95 \% \mathrm{BCa} \mathrm{Cl}[-9.91,-.40] \mathrm{p}<.05)$.

Table 3. The influence of motivational orientation on enjoyment.

\begin{tabular}{|c|c|c|c|c|c|}
\hline & $\beta$ & $\mathbf{R}^{2}$ & $\Delta \mathbf{R}^{2}$ & $t$ & $\mathbf{F}$ \\
\hline Step 1 & & .069 & .053 & 17.504 & $4.382^{*}$ \\
\hline Age & .046 & & & & \\
\hline Gender & $-.252^{*}$ & & & & \\
\hline Step 2 & & .431 & .379 & 7.233 & $8.334^{* *}$ \\
\hline Age & .052 & & & & \\
\hline Gender & $-.195^{*}$ & & & & \\
\hline Task-Orient & .018 & & & & \\
\hline Ego-Orient & -.132 & & & & \\
\hline Intrinsic & .183 & & & & \\
\hline Integrated & $.316^{*}$ & & & & \\
\hline Identified & .087 & & & & \\
\hline Introjected & -.012 & & & & \\
\hline Extrinsic & -.022 & & & & \\
\hline Amotivation & $-.240^{*}$ & & & & \\
\hline
\end{tabular}

\section{DISCUSSION}

This investigation sought to identify the motivational orientation and level of physical activity enjoyment of transplant athletes who attended the 2019 WTG, and to determine the causal relationship between their motivational behaviour and enjoyment. The findings support the authors' first hypothesis revealing a motivational profile that is represented by heightened levels of task orientation and constructive/autonomous motivational behaviour (intrinsic, identified and integrated dimensions) with moderate to high levels of perceived enjoyment. This finding is warranted as task orientation is not only positively linked to the engagement in health-related behaviour (Ahmed et al., 2017) and exercise cooperation (Lameiras, Almeida, \& Garcia-Mas, 2014), but also associated with a heightened level of self-efficacy (Cottrell, 2018) and adherence to post-surgery rehabilitation exercise recommendations (Chan, Lonsdale, Ho, Yung, \& Chan, 2009). Moreover, the athletes' associated high levels of self-regulatory behaviour characterised by inherent interest/satisfaction, feelings of congruency, and personal importance (intrinsic, integrated and identified respectively) are supported by the dialectical aspect of the SDT that assumes that sport (social context) offers individuals valuable opportunity for basic need satisfaction (autonomy, competence and relatedness) that could facilitate their inherent feelings of interest and consummation (Standage \& Ryan, 2019). Slapak (2005, 
p.24) upholds this notion approving that sport for transplant recipients might not automatically be a treat but offers a "vital vehicle" that enables full integration and demonstration of competence.

The athletes' positive affective response to physical activity is not surprising as enjoyment is considered to be a key construct in explaining athletes' motivational involvement in sports (Liukkonen, 1998); whereas a lack of enjoyment is usually a principal reason for athletes' abandonment from sports (Gardner et al., 2017). Despite the female athletes' moderately high levels of reported enjoyment, male athletes in the sample proved to derive an even greater amount of enjoyment from physical activity. This finding corroborates gender differences noted in leisure-time physical activity engagement among adults, which identified that males are more motivated by activity enjoyment, whilst females are more motivated by health reasons or aesthete (Azevedo et al., 2007). The fact that women are more likely to engage in health-care seeking and healthcare consumptive behaviour than men might also explain this difference (Tenenbaum, Nordeman, Sunnerhagen, \& Gunnarsson, 2017). Nevertheless, available research on elderly people verify that women are less likely than men to engage in physical activities that are skill demanding, vigorous, competitive, and done outdoors (van Uffelen, Khan, \& Burton, 2017). This notion is evident with a larger representation of males than females at the WTG as well as in the participation of the present investigation.

The second hypothesis of the investigation was also retained since enjoyment correlated significantly and positively with all constructive dimensions of motivation (task, orientation, intrinsic, integrated, and identified) and both significantly and negatively with some controlled motivational factors (extrinsic and amotivation). Similar findings are reported in studies that primarily aimed to translate and validate the psychometric properties of the physical activity enjoyment scale in a large sample of Portuguese athletes (Monteiro et al., 2017) and within a Spanish context (Moreno, González-Cutre, Martínez, Alonso, \& López, 2008). Based on the tenets of the Organismic Integration Theory (OIT; Deci \& Ryan, 1985 [mini theory within SDT]), athletes' active and spontaneous engagement in sports that are aimed at personal growth and improvement are likely to derive a greater sense of enjoyment from their efforts and accomplishments (Ryan \& Deci 2017). Thus, the positive correlation between task orientation and enjoyment is not unfounded.

Furthermore, as mentioned earlier in the text, athletes level of enjoyment in sport is largely dependent on the satisfaction of their basic psychological need for relatedness, autonomy and competence, which is representative of integrated and identified dimensions of motivation (Ryan \& Deci, 2017). Underscoring the Cognitive Evaluation Theory (COT; Deci \& Ryan, 1980 [mini theory within SDT]), Standage and Ryan (2019) concede that the satisfaction of these needs explains individuals' optimal motivational functioning that is coherently reflected by one's internal regulatory motivation (intrinsic motivation). In this regard, athletes' engagement in sports activities is very likely a self-determined form of behavioural regulation that emanates from the inherent feelings of satisfaction and enjoyment (resultant of their basic psychological needs being satisfied); hence the positive correlation observed between intrinsic motivation and enjoyment. Likewise, the OIT (Deci \& Ryan, 1985) profess that athletes who are motivated by extrinsic factors (e.g. rewards, contingent, approval-contingent) will enjoy less control resulting in frustrating experiences of autonomy and diminish intrinsic motivation, that is essentially associated with less enjoyment, well-being and performance (Standage \& Ryan, 2019). Standage and Ryan (2019) further explain that amotivation in more extreme instances is characteristic by the belief that the activity is unimportant and athletes in this respect, will not perceive any contingency between sport participation and the expected outcome(s). Not only is this notion verified with the significant negative association noted between extrinsic motivation and athletes' level of enjoyment in the findings of the present study, but it also explains why amotivation is negatively associated with enjoyment as well as a significant negative predictor thereof (enjoyment). The latter findings are supported by Garcia-Mas et al. (2010) and Monteiro et al. (2017) suggesting that athletes who are motivated 
by rewards and/or other approval-contingent factors are less likely to enjoy sport, similarly to those who feel that sport might not hold any inherent value or meaning in their life.

Even though the results of the present investigation did not consider the influence of role players such as caregivers or identify the exact factors that contribute to transplant athletes' sport motivational experiences, some practical value can be deducted from the findings. The motivational profile associated with sport participation after organ transplant surgery along with the identified causative links with enjoyment give caregivers, physical therapists, trainers and organisers of related competition events a good point of reference to evaluate, monitor, guide and verify their practices. Especially with the forced changes imposed by the current global COVID-19 pandemic that has resulted in limited/altered exercise environments, social distancing measures and essentially the cancellation of transplant competition events such as the 2021 WTG in the USA with an ongoing review yet to confirm the 2022 World Transplant Winter Games and the next Summer Games in 2023 (World Transplant Games Federation, 2020). Transplant athletes too are provided with information unique to them, which could be useful in the evaluation of their own views of competence, motivational orientation towards sport participation along with the potential implications on enjoyment (with the noted difference in gender). Despite this investigation's contribution, further research should address the limitations of this study by accounting for the number of WTG competitions attended by these athletes (or years of active participation), establishing the views of OTR athletes from non-English speaking nations, and also investigate socio-environmental influences such as the role of caregivers and access to/availability of informed sports trainers and coaches. In our informal talks with the athletes during data collection, some athletes resounded that not being in full-time employment augmented their motivation to take up a sport, as they have added opportunity to train and recover from training, which makes sport essentially more enjoyable. Thus, prompting the need to further investigate the influence of other socioenvironmental life stressors and levels of fatigue on transplant athletes' motivational experiences.

\section{CONCLUSION}

Motivation and enjoyment are prime factors in the initiation and continuance of physical activity (Bauman et al., 2012; Allender, Cowburn, \& Foster 2006) with motivation being the most critical psychological barrier and/or facilitator to physical activity reported by transplant recipients (Sanchez et al., 2007; van Adrichem et al., 2016). This along with a noted increase in transplant athletes competing in conventional organised sports events (Derom, 2009; Wright et al., 2019), the present investigation's focus is warranted. Also, seeing that the WTG federation has announced endeavours to host a 2020 competition in virtual format due to the COVID-19 pandemic (World Transplant Games Federation, 2020), which might impact athletes' competition and sport motivational experiences. Moreover, the noted health and well-being implications that result from organ transplant surgery make transplant athletes a vulnerable composite of society (Derom, 2009), which necessitate accurate understanding to allow for informed athlete-centred services. Considering this, the current investigation uncovered that transplant athletes exhibit task mastery as achievement goals with a motivational contort that is characterised by a sense of personal interest, value, and congruence. It is essentially advised that these autonomous regulatory behaviours be garnered in transplant recipients looking to start/continue sport participation as it proved to be prime determinants of athletes' level of enjoyment and most likely sustained levels of participation. 


\section{ACKNOWLEDGMENTS}

The authors herewith, declare no probable conflict of interest with respect to the research, authorship, and/or publication of this article. No financial support for the research, authorship, and /or publication of this article was received.

\section{REFERENCES}

Adie, J. W., Duda, J. L., \& Ntoumanis, N. (2008). Achievement goals, competition appraisals, and the psychological and emotional welfare of sport participants. Journal of Sport and Exercise Psychology, 30(3), 302-322. https://doi.org/10.1123/jsep.30.3.302

Aijing, L., Wenzhao, X., Wei, W., Qiquan, W., \& Xuantong, D. (2016). Public opinion on organ donation after death and its influence on attitudes toward organ donation. Annals of Transplantation, 515-524. https://doi.org/10.12659/aot.899268

Allender, S., Cowburn, G., \& Foster, C. (2006). Understanding participation in sport and physical activity among children and adults: a review of qualitative studies. Health education research, 21(6), 826835. https://doi.org/10.1093/her/cyl063

Azevedo, M. R., Araújo, C. L. P., Reichert, F. F., Siqueira, F. V., da Silva, M. C., \& Hallal, P. C. (2007). Gender differences in leisure-time physical activity. International Journal of Public Health, 52(1), 815. https://doi.org/10.1007/s00038-006-5062-1

Bauman, A. E., Reis, R. S., Sallis, J. F., Wells, J. C., Loos, R. J., Martin, B. W., \& Lancet Physical Activity Series Working Group. (2012). Correlates of physical activity: why are some people physically active and others not?. The Lancet, 380(9838), 258-271. https://doi.org/10.1016/s0140-6736(12)60735-1

Cairney, J., Kwan, M. Y., Velduizen, S., Hay, J., Bray, S. R., \& Faught, B. E. (2012). Gender, perceived competence and the enjoyment of physical education in children: a longitudinal examination. International Journal of Behavioral Nutrition and Physical Activity, 9(1), 26-33. https://doi.org/10.1186/1479-5868-9-26

Chan, D. K., Lonsdale, C., Ho, P. Y., Yung, P. S., \& Chan, K. M. (2009). Patient motivation and adherence to postsurgery rehabilitation exercise recommendations: the influence of physiotherapists' autonomysupportive behaviors. Archives of Physical Medicine and Rehabilitation, 90(12), 1977-1982. https://doi.org/10.1016/i.apmr.2009.05.024

Crane, J., \& Temple, V. (2015). A systematic review of dropout from organized sport among children and youth. European Physical Education Review, 21(1), 114-131. https://doi.org/10.1177/1356336X14555294

Deci, E. L., \& Ryan, R. M. (2012). Self-determination theory. In A. W. K. P. A. M. Van Lange, \& E. T. Higgins (Ed.), Handbook of theories of social psychology (pp. 416-436). London, Sage Publications Ltd. https://doi.org/10.4135/9781446249215.n21

Derom, I. (2009). Identity and motives of participants at a cause-related sport event. (Master of Human Kinetics). University of Windsor.

Didsbury, M., McGee, R. G., Tong, A., Craig, J. C., Chapman, J. R., Chadban, S., \& Wong, G. (2013). Exercise training in solid organ transplant recipients: a systematic review and meta-analysis. Transplantation, 95(5), 679-687. https://doi.org/10.1097/tp.0b013e31827a3d3e

Duda, J., Fox, K., Biddle, S., \& Armstrong, N. (1992). Children's achievement goals and beliefs about success in sport. British Journal of Educational Psychology, 62(3), 313-323. https://doi.org/10.1111/j.2044-8279.1992.tb01025.x 
Duda, J., \& Whitehead, J. (1998). Measurement of goal perspectives in the physical domain. In W. J. Duda JL (Ed.), Advances in sport and exercise psychology measurement (Vol. 172, pp. 21-48). MorgantownWV: Fitness Information Technology.

Garcia-Mas, A., Palou, P., Gili, M., Ponseti, X., Borras, P. A., Vidal, J., .. Sousa, C. (2010). Commitment, enjoyment and motivation in young soccer competitive players. The Spanish Journal of Psychology, 13(2), 609-616. https://doi.org/10.1017/s1138741600002286

Gardner, L. A., Magee, C. A., \& Vella, S. A. (2017). Enjoyment and behavioral intention predict organized youth sport participation and dropout. Journal of Physical Activity and Health, 14(11), 861-865. https://doi.org/10.1123/jpah.2016-0572

GOV.UK. (2019). Opt-out organ donation: Max and Keira's Bill passed into law. Retrieved from https://www.gov.uk/government/news/opt-out-organ-donation-max-and-keira-s-bill-passed-into-law

Gregg, M. J., Jenny, O., \& Hall, C. R. (2016). Examining the relationship between athletes' achievement goal orientation and ability to employ imagery. Psychology of Sport and Exercise, 24, 140-146. https://doi.org/10.1016/i.psychsport.2016.01.006

Hinton, P. R., McMurray, I., \& Brownlow, C. (2014). SPSS explained. East Sussex, Routledge.

Hodge, K., Allen, J. B., \& Smellie, L. (2008). Motivation in Masters sport: achievement and social goals. Psychology of Sport and Exercise, 9(2), 157-176. https://doi.org/10.1016/j.psychsport.2007.03.002

Hodge, K., Lonsdale, C., \& Jackson, S. A. (2009). Athlete engagement in elite sport: an exploratory investigation of antecedents and consequences. The Sport Psychologist, 23(2), 186-202. https://doi.org/10.1123/tsp.23.2.186

Johnson, U., Hinic, H., Billström, A., \& Gäbel, H. (2013). Transplant recipients' experience of participation at the World Trans-plant Games in Gothenburg 2011: a study of psychological well-being. Open Transplantation Journal, 7, 1-9. https://doi.org/10.2174/1874418420130605002

Kendzierski, D., \& DeCarlo, K. J. (1991). Physical activity enjoyment scale: two validation studies. Journal of Sport and Exercise Psychology, 13(1), 50-64. https://doi.org/10.1123/jsep.13.1.50

Liukkonen, J. (1998). Enjoyment as an affective outcome of motivational orientation and perceived motivational climate. Paper presented at the 2nd Annual Congress of the European College of Sport Science, Copenhagen.

Milyavskaya, M., \& Koestner, R. (2011). Psychological needs, motivation, and well-being: a test of selfdetermination theory across multiple domains. Personality and Individual Differences, 50(3), 387391. https://doi.org/10.1016/j.paid.2010.10.029

Monteiro, D., Nunes, G., Marinho, D. A., Couto, N., Antunes, R., Moutão, J., \& Cid, L. (2017). Translation and adaptation of the physical activity enjoyment scale (PACES) in a sample of Portuguese athletes, invariance across genders nature sports and swimming. Revista Brasileira de Cineantropometria \& Desempenho Humano, 19(6), 631-643. https://doi.org/10.5007/1980-0037.2017v19n6p631

Moreno, J.-A., González-Cutre, D., Martínez, C., Alonso, N., \& López, M. (2008). Propiedades psicométricas de la Physical Activity Enjoyment Scale (PACES) en el contexto español. Estudios de Psicología, 29(2), 173-180. https://doi.org/10.1174/021093908784485093

Motl, R. W., Dishman, R. K., Saunders, R., Dowda, M., Felton, G., \& Pate, R. R. (2001). Measuring enjoyment of physical activity in adolescent girls. American Journal of Preventive Medicine, 21(2), 110-117. https://doi.org/10.1016/S0749-3797(01)00326-9

Neale, J., Smith, A. C., \& Bishop, N. C. (2017). Effects of exercise and sport in solid organ transplant recipients: a review. American Journal of Physical Medicine and Rehabilitation, 96(4), 273-288. https://doi.org/10.1097/phm.0000000000000599

Ntoumanis, N., \& Biddle, S. J. (1999). A review of motivational climate in physical activity. Journal of Sports Sciences, 17(8), 643-665. https://doi.org/10.1080/026404199365678 
Pelletier, L. G., Rocchi, M. A., Vallerand, R. J., Deci, E. L., \& Ryan, R. M. (2013). Validation of the revised sport motivation scale (SMS-II). Psychology of Sport and Exercise, 14(3), 329-341. https://doi.org/10.1016/i.psychsport.2012.12.002

Romanová, M., \& Sollár, T. (2019). Enjoyment of physical activity and perception of success in sports high school students. Ad Alta: Journal of Interdisciplinary Research, 9(1),249-251.

Ryan, R. M., \& Deci, E. L. (2007). Active human nature: Self-determination theory and the promotion and maintenance of sport, exercise, and health. In M. S. H. N. L. D. Chatzisarantis (Ed.), Intrinsic Motivation and Self-Determination in Exercise and Sport (pp. 1-20). Champagne, Illinois: Human Kinetics Publishing, In.

Ryan, R. M., \& Deci, E. L. (2017). Self-determination theory: Basic psychological needs in motivation, development, and wellness. Champagne, Illinois: Guilford Publications. https://doi.org/10.7202/1041847ar

Sallis, J. F., Prochaska, J. J., \& Taylor, W. C. (2000). A review of correlates of physical activity of children and adolescents. Medicine and Science in Sports and Exercise, 32(5), 963-975. https://doi.org/10.1097/00005768-200005000-00014

Sánchez-Miguel, P. A., Leo, F. M., Sánchez-Oliva, D., Amado, D., \& García-Calvo, T. (2013). The importance of parents' behavior in their children's enjoyment and amotivation in sports. Journal of Human Kinetics, 36(1), 169-177. https://doi.org/10.2478/hukin-2013-0017

Sanchez, Z. V., Cashion, A. K., Cowan, P. A., Jacob, S. R., Wicks, M. N., \& Velasquez-Mieyer, P. (2007). Perceived barriers and facilitators to physical activity in kidney transplant recipients. Prog Transplant, 17(4), 324-331. https://doi.org/10.1177/152692480701700411

Sari, I. (2015). Satisfaction of basic psychological needs and goal orientation in young athletes: A test of basic psychological needs theory. Kinesiology: International Journal of Fundamental and Applied Kinesiology, 47(2), 159-168.

Schneider, R., Harrington, M., \& Tobar, D. (2017). Goal orientation and how a task or ego mentality can affect the enjoyment for college hockey players. College Student Journal, 51(1), 57-62.

Slapak, M. (2005). Sport for the transplant athlete-just harmless fun or a valuable tool? Annals of Transplantation, 10(4), 24-28.

Standage, M., Duda, J. L., \& Pensgaard, A. M. (2005). The effect of competitive outcome and taskinvolving, ego-involving, and cooperative structures on the psychological well-being of individuals engaged in a co-ordination task: a self-determination approach. Motivation and Emotion, 29(1), 41 68. https://doi.org/10.1007/s11031-005-4415-z

Standage, M., \& Ryan, R. M. (2019). Self-determination theory in sport and exercise. Handbook of sport psychology (4th ed., pp. 352-378). Hoboken, NJ: Wiley.

Tenenbaum, A., Nordeman, L., Sunnerhagen, K. S., \& Gunnarsson, R. (2017). Gender differences in care-seeking behavior and healthcare consumption immediately after whiplash trauma. PloS One, 12(4), e0176328. https://doi.org/10.1371/journal.pone.0176328

Tukey, J. (1962). The future of data analysis. Annals of Mathematical Statistics, 33(1), 1-67. https://doi.org/10.1214/aoms/1177704711

Vallerand, R. J. (2007). Intrinsic and extrinsic motivation in sport and physical activity. In G Tenenbaum \& R.C Eklund, Handbook of sport psychology, 3 (59-83). New Jersey, Wiley \& Sons, Inc. https://doi.org/10.1002/9781118270011.ch3

van Adrichem, E. J., van de Zande, S. C., Dekker, R., Verschuuren, E. A., Dijkstra, P. U., \& van der Schans, C. P. (2016). Perceived barriers to and facilitators of physical activity in recipients of solid organ transplantation, a qualitative study. PloS One, 11(9), e0162725. https://doi.org/10.1371/journal.pone.0162725 
van Uffelen, J. G., Khan, A., \& Burton, N. W. (2017). Gender differences in physical activity motivators and context preferences: a population-based study in people in their sixties. BMC Public Health, 17(1), 624-634. https://doi.org/10.1186/s12889-017-4540-0

Visek, A. J., Achrati, S. M., Mannix, H. M., McDonnell, K., Harris, B. S., \& DiPietro, L. (2015). The fun integration theory: toward sustaining children and adolescents sport participation. Journal of Physical Activity and Health, 12(3), 424-433. https://doi.org/10.1123/ipah.2013-0180

Wallhead, T. L., \& Buckworth, J. (2004). The role of physical education in the promotion of youth physical activity. Quest, 56(3), 285-301. https://doi.org/10.1080/00336297.2004.10491827

Weinberg, R. S., \& Gould, D. (2018). Foundations of sport and exercise psychology, 7E. Champaign IL, Human Kinetics.

World Transplant Games. (2019). Retrieved from http://worldtransplantgames.org

World Transplant Games Federation. (2020). Retrieved from https://wtgf.org/2021-world-transplantgames-cancelled/

Wright, S. L., Bloxham, A., Hames, T., \& Price, M. (2019). Therapeutic perceptions in management of transplant athletes at transplant games. Physical Therapy in Sport, 39, 114-119. https://doi.org/10.1016/i.ptsp.2019.07.003

Yli-Piipari, S., Barkoukis, V., Jaakkola, T., \& Liukkonen, J. (2013). The effect of physical education goal orientations and enjoyment in adolescent physical activity: a parallel process latent growth analysis. Sport, Exercise, and Performance Psychology, 2(1), 15-31. https://doi.org/10.1037/a0029806

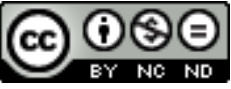

This work is licensed under a Attribution-NonCommercial-NoDerivatives 4.0 International (CC BY-NC-ND 4.0). 